\title{
Double-action Die Compaction of Fe-Al Composite Powder- A Study by MPFEM Simulation
}

\author{
Jun-Wei $\mathrm{LI}^{1, \mathrm{a}}$ and Xi-Zhong $\mathrm{AN}^{2, \mathrm{~b},{ }^{*}}$ \\ ${ }^{1}$ School of Mechanical Engineering, Northeastern University, Shenyang 110004, PR China \\ 2 School of Metallurgy, Northeastern University, Shenyang 110004, PR China \\ a20145338@stu.neu.edu.cn \\ banxz@mail.neu.edu.cn \\ * Corresponding author
}

Keywords: MPFEM modeling, particulate scale simulation, Fe and Al composite powders, double-action die compaction, densification mechanism

\begin{abstract}
To identify the densification process and corresponding mechanism, double-action die compaction of Fe-Al composite powder (with $20 \mathrm{wt} \% \mathrm{Al}$ ) was modeled by multi-particle finite element method (MPFEM) from particulate scale in 2D. The initial packing structure generated by discrete element method (DEM) was input into FEM model where the mesh division of each particle was discretized. During compaction, macro and micro properties of the compacts were characterized and compared with those from single-action die compaction. The results show that with the same initial packing structure, double-action compaction can create dense compact with more uniform stress and relative density distributions at relatively low pressure. Densification mechanism analyses indicate that double-action compaction can more effectively improve the particle rearrangement to realize the dense packing structure compared with single action compaction when the pressure is low, in the former case large voids or pores have almost been eliminated, which is the precondition for the formation of high quality compact. With the increase of the pressure, further rearrangement and elastic and plastic deformation of $\mathrm{Fe}$ and $\mathrm{Al}$ particles can be observed; in this stage, the densification is mainly due to the plastic deformation of $\mathrm{Al}$ particles to fill their adjacent interstices. At high pressure, the compact shows bulk behavior, and some isolated enclosed pores are remained in the final compact. MPFEM simulation demonstrates that the final compact obtained in double-action compaction shows lower stresses/contact forces, and the stress distribution and particle deformation are more uniform.
\end{abstract}

\section{Introduction}

In recent years, Fe-Al intermetallic compounds are attractive due to their unique properties such as low cost, low density, ease of fabrication, good high temperature mechanical property, excellent resistance to oxidation and corrosion, high electrical resistivity, as well as dual characteristics of both structural and functional materials etc [1-18]. These properties have led to the identification of many potential uses, including high temperature structural materials, sintered porous gas-metal filters, heating elements, furnace fixtures, heat-exchanger piping, automobile and other industrial valve components, catalytic converter substrates, and components for molten salt applications [3-5,9,19,20]. Therefore, in the past decades much effort was paid in the production of Fe-Al intermetallics, where the commonly used methods are melting/casting, mechanical alloying, combustion synthesis with thermo-mechanical treatment, and powder metallurgy (PM) etc [9,14,21], among which PM processing has increasingly attracted researchers' eyes due to its unique advantages in structure and size control, property improvement, and net shape or near net shape forming [14]. However, most studies in previous work using PM method for the preparation of Fe-Al intermetallics were mainly carried out in physical experiments. In comparison, corresponding numerical studies were limited. Actually, the forming or compaction in PM procedures is also of key importance, since a high performance compact with high relative density, small and uniform pore size distribution, and 
uniform density and stress distributions is the precondition for high quality porous Fe-Al product.

Earlier numerical work on the compaction of Fe-Al composite powders starts from single-action die compaction (also called single compaction) from different scales. Wu et al. firstly carried out finite element simulations of uniaxial compaction of $\mathrm{Fe}-\mathrm{Al}$ composite powders from particulate scale in 2D [22]. In their work, different initial packing structures such as square and hexagonal packings before compaction were considered and the deformation as well as the contact pressure distribution at the contact area during compaction were characterized. While they are mainly focusing on the compaction of ordered initial packing structures, for the compaction of random initial packings which are frequently appeared in real process is not studied in their work. Recently, using traditional finite element method (FEM) and multi-particle FEM (MPFEM) method, Han et al. respectively carried out systematic studies on the single-action die compaction of Fe-Al composite powders with random initial packing structures from both continuous scale and discrete scale $[17,18]$. In their work, the macro and micro properties of the compacts as well as the densification mechanisms were characterized and analyzed. Generally, previous numerical studies on the compaction of Fe-Al composite powders were mainly focusing on single-action die compaction, where the relative density and stress at the bottom end (far from the upper punch) of the compact are very low, which will create defects in subsequent processing procedures. This disadvantage can be overcome by the application of the so called double-action die compaction (also called double compaction), while the work in this regards is very sparse. Especially the synergistic effects of upper and lower punches on the rearrangement of $\mathrm{Fe}$ and $\mathrm{Al}$ particles, their deformation, as well as the macro and micro properties have not been found the previous literatures and need to be thoroughly studied.

In this paper, the double-action die compaction of Fe-Al composite powder was modelled by MPFEM method in 2D. The initial random packing structure generated by DEM method was imported into FEM model. The effects of compaction pressure on relative density and distribution, stress and distribution, particle deformation, void filling behavior, and contact forces in the compact during compaction were systematically studied and analyzed. The highlights of the present work can be summarized as follows: (1) Double-action die compaction of Fe-Al composite powder was numerically conducted by multi-particle finite element method from particulate scale; (2) The effects of compaction pressure on the packing densification of the Fe-Al composite powders were studied and compared with the single action die compaction; (3) The compaction dynamics and densification mechanisms were identified based on the individual particle deformation and force behavior.

\section{Simulation Methods and Conditions}

\section{Simulation Methods}

To more realistically model the double-action die compaction of Fe-Al composite powder, DEM and MPFEM are respectively applied in the numerical simulation. Here, we use DEM to generate initial packing structure before compaction and use MPFEM for compaction. DEM [23-26] and MPFEM $[18,27]$ simulation methods in corresponding processes have been successfully utilized in our previous work, therefore, the details of these methods will not be illustrated here. Readers who are interested please refer to our recently published papers. Once the initial packing is generated, it will be imported as an input into FEM model for mesh division and subsequent compaction. Fig. 1 shows the morphology of initial random packing structure of Fe-Al composite powder with mesh division of all particles, where Fig. 1 (b) gives the zoom in for the mesh division of each particle with 132 units and 169 nodes. It needs to note that in order to compare with the results from single-action die compaction, we adopt the same initial packing structure of Fe-Al composite powder with $\mathrm{Al}$ content of $20 \mathrm{wt} . \%$ and the same mesh division for compaction [18]. 


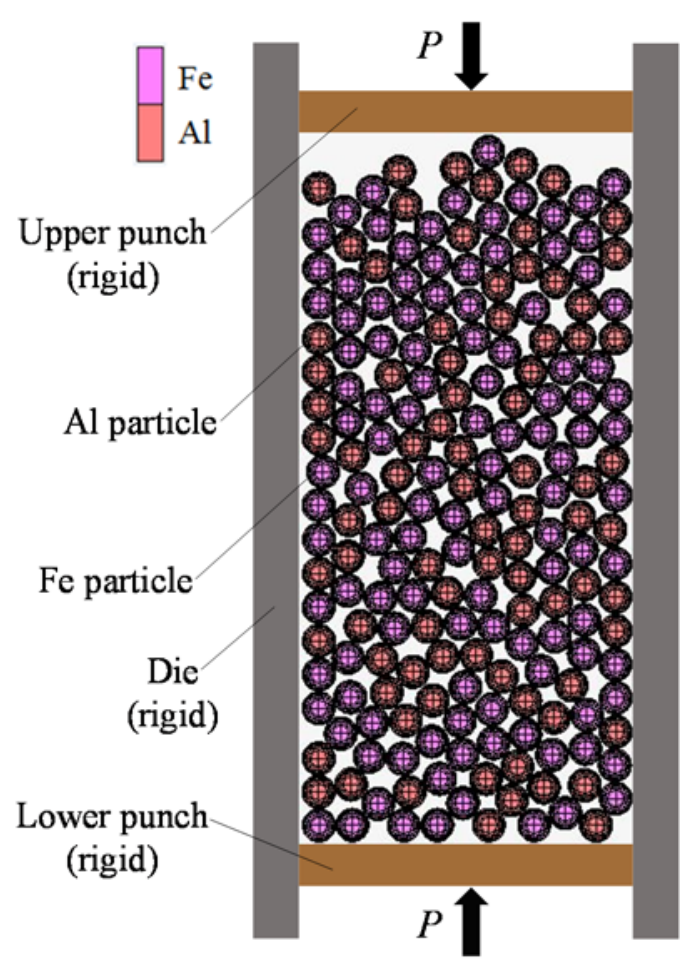

(a)

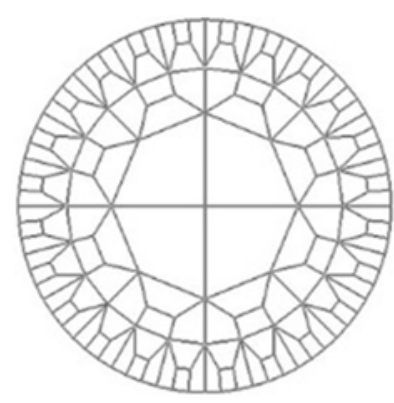

(b)

Fig. 1 DEM generation of initial random packing structure of Fe-Al composite powder (a) and mesh division in individual particle (b) before double-action die compaction.

\section{Simulation Conditions}

In the MPFEM simulation, both the Fe and $\mathrm{Al}$ particles are in equal size with $1 \mathrm{~mm}$ in diameter and are set to be the elastoplastic body. The punches and the die are rigid. Table 1 gives the materials parameters used in the simulation. During compaction, boundary conditions are summarized as follows: displacement boundary condition is imposed via rigid upper and lower punches. The position of the rigid die wall is fixed, and the change in relative density of the compact is determined by the change in displacement of the punches. With the downward motion of the upper punch and the upward motion of the lower punch, interactions between those particles in contact with the punches will initially be created and then the forces acting on these particles will be transmitted to their neighboring particles. This process will continue until the forces act on the whole compact and the preset compaction pressure are reached.

Table 1 Materials parameters used in the simulation.

\begin{tabular}{ccccc}
\hline Materials & $\begin{array}{c}\text { Young's modulus } \\
{[E / \mathrm{GPa}]}\end{array}$ & $\begin{array}{c}\text { Poisson's } \\
\text { ratio }[\mathrm{v}]\end{array}$ & $\begin{array}{c}\text { Strength } \\
\text { coefficient }[\mathrm{K} / \mathrm{MPa}]\end{array}$ & $\begin{array}{c}\text { Hardening } \\
\text { index }[\mathrm{n}]\end{array}$ \\
\hline $\mathrm{Fe}$ & 120.00 & 0.25 & 575.3 & 0.237 \\
$\mathrm{Al}$ & 62.59 & 0.33 & 225.9 & 0.050 \\
\hline
\end{tabular}

It needs to clarify that the simulation results are not affected by the strain rate since materials are assumed to be not strain-rate sensitive. Each particle in the composite powder is independent and deformable, the relationship between the positions of particles can be determined in a contact table to judge their contact state in model setup. Upon compaction, the contact between particles was controlled by 'node to segment method' which is widely used in MPFEM simulation [18,27,28]. The friction coefficient between the particles is set to be 0.2 . The punches and the die are rigid with smooth surface to reduce their friction with the powder. The accuracy of simulation results using MPFEM method is closely related to the mesh division of discrete model. The shapes and boundary of engineering structures are normally very complicated, and the initial mesh division in the model might not guarantee the accuracy of the results or the computation efficiency. According to the error 
criterion, local mesh adaptability [27-31] can automatically define the density of meshes in finite element analysis, which makes it possible by using optimized meshes in MPFEM model for accurate and efficient numerical computation. The global remeshing [32] can help to correct mesh distortions with excessive deformation, and then remeshes the model to ensure that subsequent calculations can be run smoothly. So in this study, we adopt local adaptivity and global remeshing to define each particle in the model to improve the accuracy of computation. Meanwhile, a modified NewtonRaphson iteration algorithm for convergence of the computation and a tangential stiffness matrix for iteration balance are adopted to minimize the amount of calculation. Once all the simulation parameters and conditions (shown in Table 2) are determined, the job will be submitted to the server with GPU acceleration for running in the commercialized MSC.Marc software.

Table 2 Modeling conditions.

\begin{tabular}{|c|c|c|}
\hline Contact definition & Load setting & Jobs \\
\hline $\begin{array}{l}\text { Particles: deformable } \\
\text { Die and punches: rigid } \\
\text { Friction between particles: } 0.2\end{array}$ & $\begin{array}{l}\text { Iteration method: full Newton- } \\
\text { Raphson algorithm } \\
\text { Convergence criterion: displacement }\end{array}$ & $\begin{array}{l}\text { Updated Lagrange for large } \\
\text { strain } \\
\text { Large deformation }\end{array}$ \\
\hline Upper punch: velocity control & & Node to segment method \\
\hline
\end{tabular}

\section{Results and Discussion}

\section{Relationship between the Relative Density and Pressure}

In a real process, the powder compaction can be affected by many factors, where the compaction (or compression) pressure $\mathrm{P}$ plays the most important role in determining the relative density $\rho=V_{\mathrm{P}} / \mathrm{V}$, where $V_{p}$ and $V$ represent the volume of particles and the volume of container (die), respectively. Fig. 2 gives the $\rho$-P relationship of $\mathrm{Fe}-\mathrm{Al}$ composite powders $(20 \mathrm{wt} . \% \mathrm{Al})$ when subjected to singleaction [18] and double-action die compactions, respectively, where the inset figures are the morphologies of compacts at different stages. The figure shows that three stages can be identified through $\rho$-P curve of double-action compaction: (1) at the initial stage, the densification is mainly attributed to the rearrangement of particles to fill the large pores in the initial loose packing at very low compression pressure (from 0-5 MPa). In this stage, the packing density of about 0.82 has been realized, which corresponds to the random close packing (RCP) state. While in single-action compaction, the packing structure in this stage is still in loose state with the packing density of about 0.80 [33]. Furthermore, in both cases the particles are only subjected to elastic deformation, and no large plastic deformation is observed; (2) with the increase of the compressing pressure (from 5-250 $\mathrm{MPa}$ ), the compaction process transmits to the second stage, where $\mathrm{P}$ is beyond the yield limit of the particles and induces large scale plastic deformation of the soft Al particles to fill their adjacent interstices for densification. At this stage, the relative density increases with the compressing pressure to a high value ( $\rho$ can be up to about 0.95 ); (3) when the relative density of the compact is more than a certain value (e.g. $\rho \geq 0.95)$, the increment of relative density with compressing pressure $(\mathrm{P} \geq 250$ $\mathrm{MPa}$ ) slows down. And the whole powder compact indicates bulk behavior. With the further increase of pressure $\mathrm{P}$, the increase of relative density $\rho$ becomes not significant. Further densification is impeded by the working hardening of particles due to the large deformation. Therefore, in the last stage of compaction, there are still some isolated enclosed small pores left in the final compact. The evolution trend of $\rho$-P curves in Fig. 2 is in good agreement with others' physical and numerical results [18,22,34]. Meanwhile, from Fig. 2 one can also find that even with the same initial packing structure and the same compaction pressure, double-action compaction can realize higher relative density than single-action compaction, which means that the former process is much more effective for densification. And even the final relative density of the compacts obtained from the two compaction processes is the same due to the sufficient high compaction pressure, however, their static structure and corresponding properties are quite different, the mechanism of which will be discussed in the following part. 


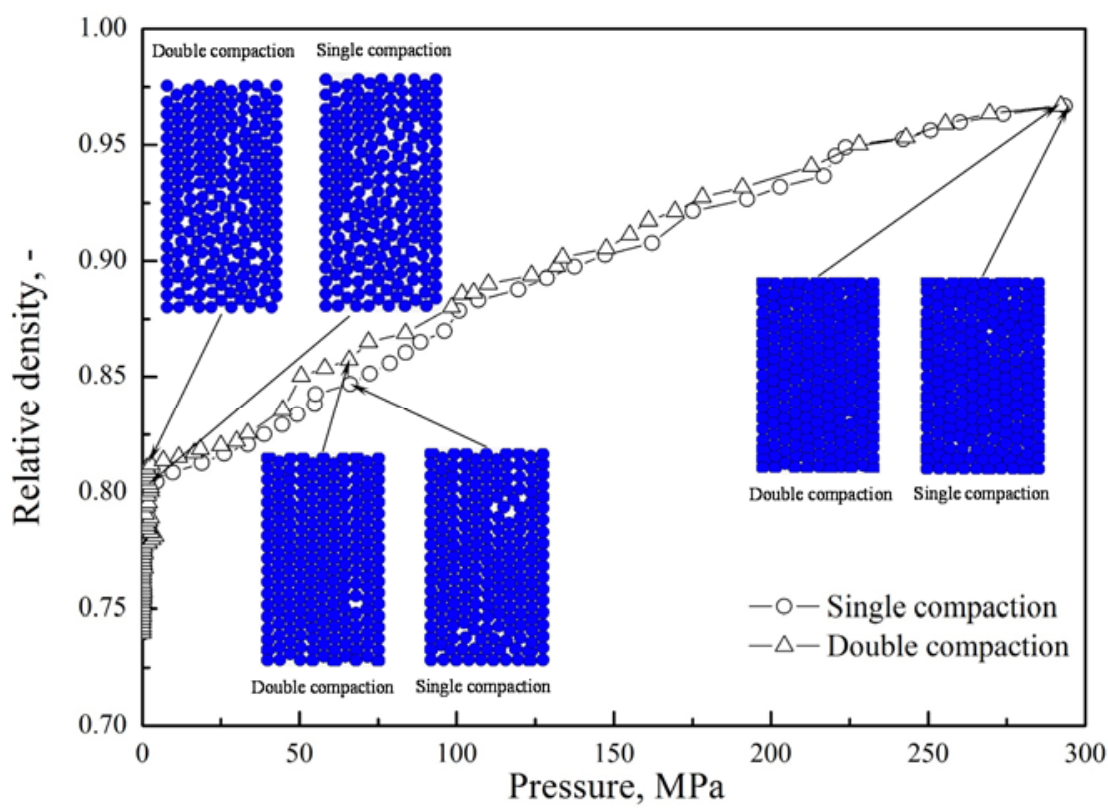

Fig. 2 Comparison of relative density-pressure relations for the same Fe-Al initial packing structure during singleaction die compaction and double-action die compaction, where the inset figures are the morphologies of compacts at different stages of the two forming processes.

To demonstrate the validity and effectiveness of the applied numerical model, our numerical results are fitted by Heckel equation which was presented in logarithmic form $[35,36]$ and given by: $\ln [1 /(1$ $-\rho)]=\mathrm{KP}+\mathrm{A}$, where $\rho$ is the relative density of the compact, $\mathrm{P}$ is applied pressure, $\mathrm{A}$ and $\mathrm{K}$ are constants. The fitting of our numerical results with the Heckel equation as shown in Fig. 3 is agreeable with high confidence, which implies the robustness and reliability of the model and the accuracy of simulation results in MPFEM.

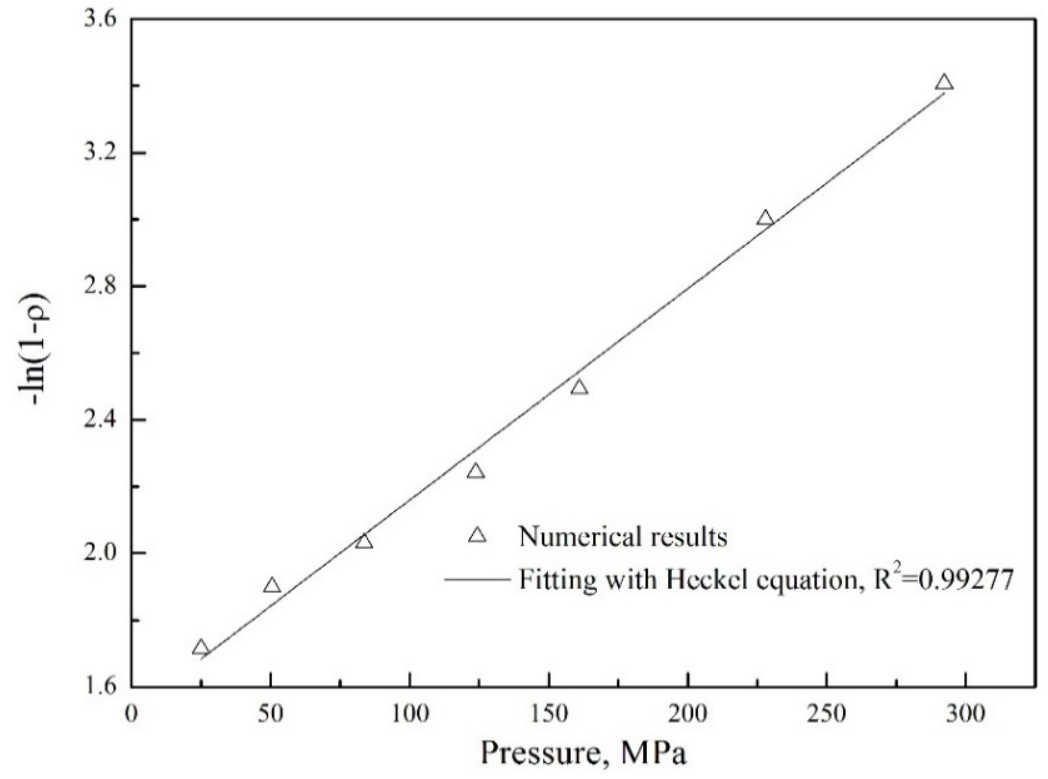

Fig. 3 Fitting of numerical results with Heckel equation [35,36].

\section{Micro Property Characterization and Densification Mechanism Analysis}

To compare the micro property difference of Fe-Al composite compacts obtained from single-action compaction and double-action compaction with the same initial packing structure, we conducted systematic analysis. Fig. 4 gives the equivalent Von Mises stress distributions and morphology evolution in the $\mathrm{Fe}-\mathrm{Al}$ composite powder compacts at different compaction stages with single-action compaction (a-e) and double-action compaction $\left(\mathrm{a}^{\prime}-\mathrm{e}^{\prime}\right)$, where: (a)-(e) correspond to the relative density of $0.804,0.829,0.902,0.934,0.967$ and $\left(\mathrm{a}^{\prime}\right)-\left(\mathrm{e}^{\prime}\right)$ correspond to the relative density of 0.813 , 
$0.835,0.905,0.940,0.967$. For easy identification, Al particles in the compacts are marked with green boundaries. The circled five particles are selected for subsequent local analysis. Fig. 4 shows that the circled loose local packing structure can be easily eliminated in double-action compaction, and the pore distribution, equivalent Von Mises stress distribution, as well as the particle deformation in the compact with double compaction are all more uniform than those in the compact with single compaction, which implies that the former process is much more effective and efficient to form the high performance Fe-Al composite compact than the latter.

The densification mechanism can be further identified by tracing the evolution of morphology and stress of the local cluster (as circled in Fig. 4) in Fig. 5. It can be seen that the large pore formed by the particles in the cluster in initial packing before compaction can be filled by its adjacent particles upon compression. Since the application of double-action compaction can greatly improve the particle rearrangement, the large pore can be easily filled by the movement of neighboring particles at relatively low pressure. In this case, the local packing is in dense packing state, no obvious plastic deformation can be observed. With the increase of the compaction pressure in both sides, the stresses between particles increase. One can find that large stresses first appear between Fe particles and gradually transfer to its neighboring Al particles. When the stress reaches the material yield limit, plastic deformation of particles occurs to further fill the interstices among them. In comparison, the same large pore structure can be very hard eliminated in single compaction due to the limited rearrangement of particles affected simply by the upper punch. Therefore, to completely fill such pore is more difficult, which needs larger compaction pressure and particle deformation. This will inevitably lead to the non-uniform stress distribution and more irregular particle deformation in the final compact.

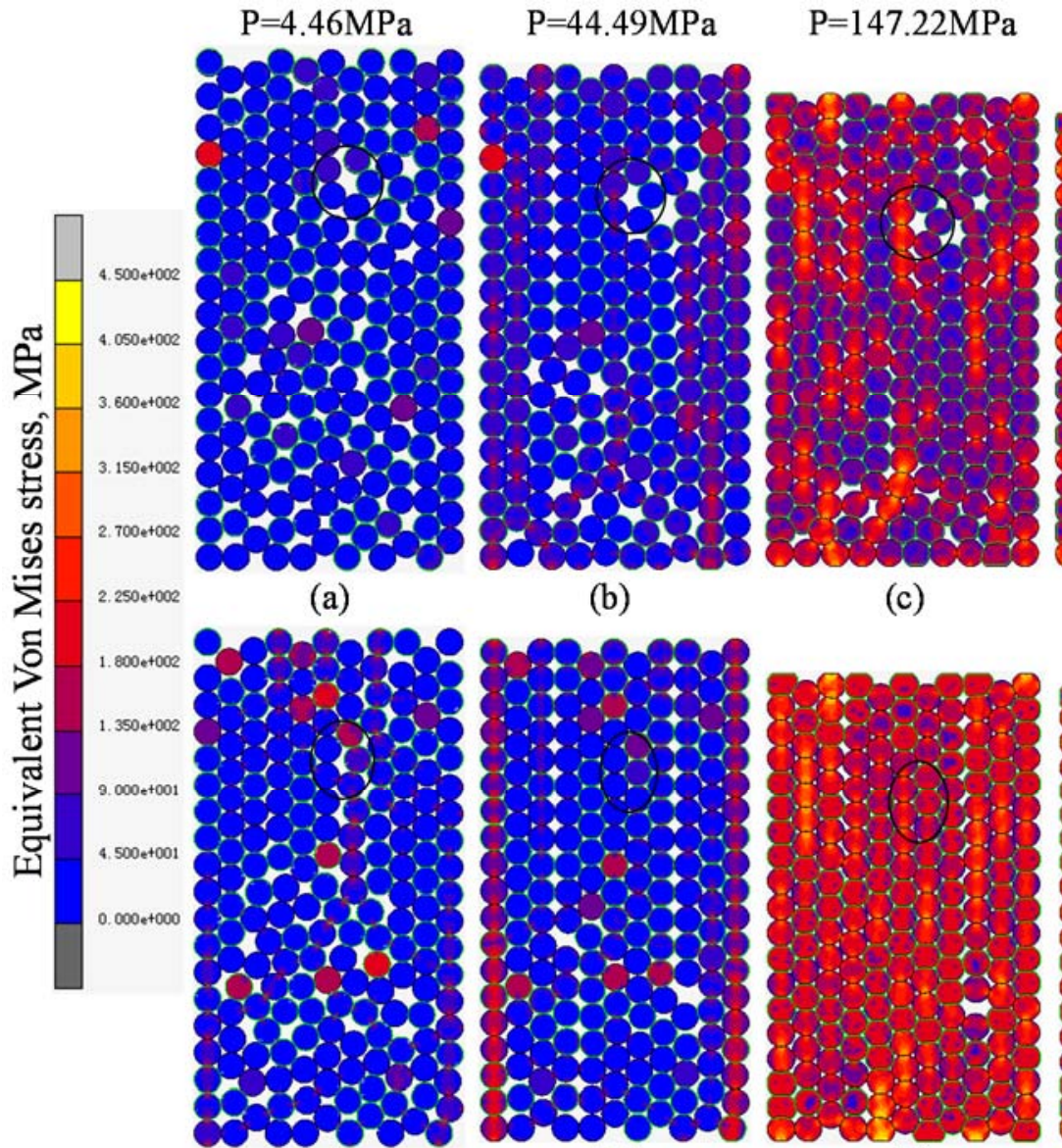

$\left(a^{\prime}\right)$ (b) (c')

$$
\mathrm{P}=212.86 \mathrm{MPa} \quad \mathrm{P}=293.53 \mathrm{MPa}
$$

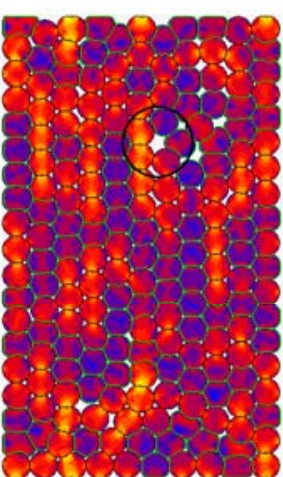

(d)

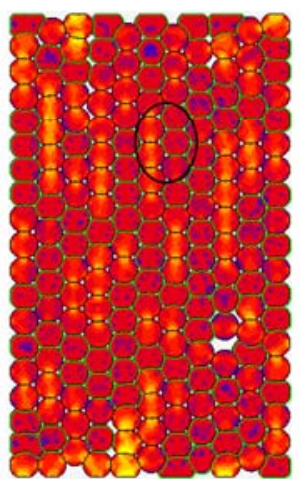

(d')

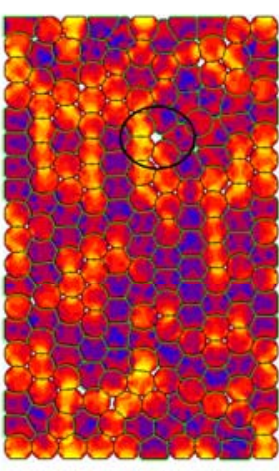

(e)

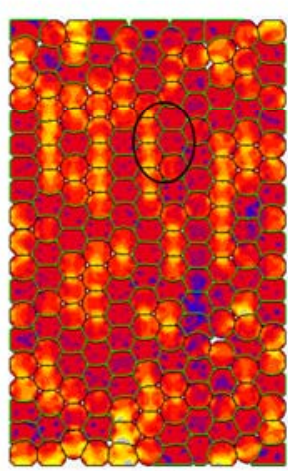

$\left(\mathrm{e}^{\prime}\right)$

Fig. 4 The equivalent Von Mises stress distributions and morphology evolution in the Fe-Al composite powder compacts at different compaction stages with single-action compaction (a-e) and double-action compaction $\left(\mathrm{a}^{\prime}-\mathrm{e}^{\prime}\right)$, where: (a)-(e) correspond to the relative density of $0.804,0.829,0.902,0.934,0.967$ and $\left(a^{\prime}\right)-\left(e^{\prime}\right)$ correspond to the relative density of $0.813,0.835,0.905,0.940,0.967$. 


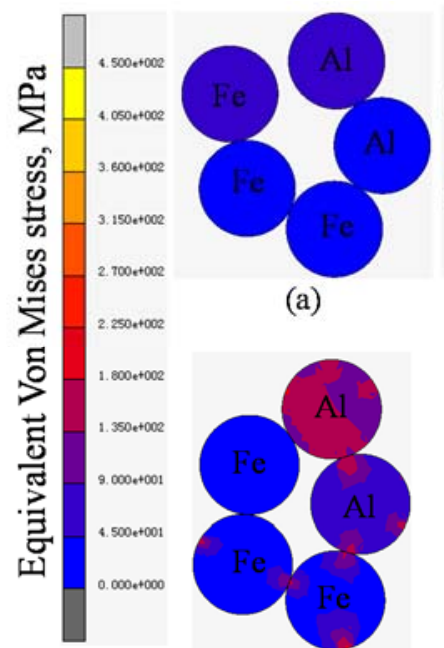

(a')

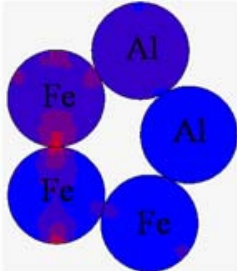

(b)

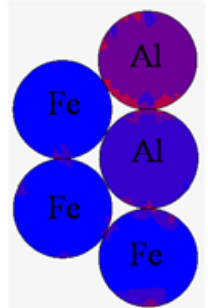

(b')

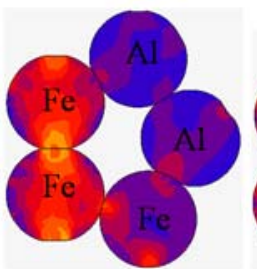

(c)

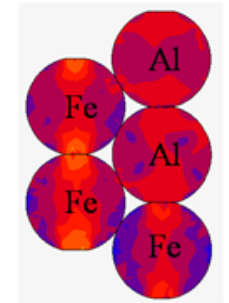

(c')

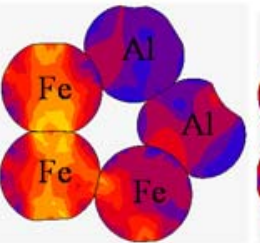

(d)

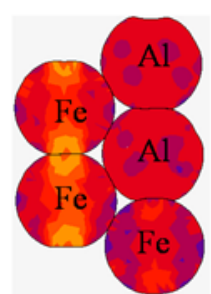

$\left(d^{\prime}\right)$

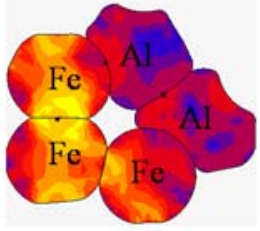

(e)

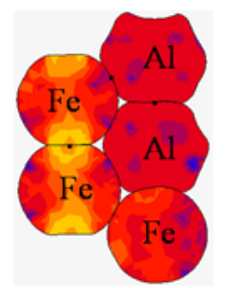

(e')

Fig. 5 The equivalent Von Mises stress distributions and morphology evolution of local clusters extracted from Fig. 4 (as circled), where the dots schematically shown at the contact area between Fe-Fe, Fe-Al, and Al-Al are the nodes of the initial contact point between these particles during compaction.

Correspondingly, the contact normal forces between particles in local structures (Please see Fig. 5) in the compacts under different compaction processes are characterized and compared as shown in Fig. 6. As indicated, the general contact formal forces in the compact in double-action compaction are much smaller and more uniform in distribution than those in the single-action compaction, which will avoid the distortion even the cracking during subsequent sintering process. The quantitative characterization of the contact normal forces at the initial contact points between particles in Figs. 5 and 6 (where the black dots in the final compacts are the schematic illustration of the initial contact points of $\mathrm{Fe}-\mathrm{Fe}, \mathrm{Fe}-\mathrm{Al}$, and $\mathrm{Al}-\mathrm{Al}$ ) in different compaction stages is performed. Fig. 7 gives the evolution of contact normal force between each pair of contacted particles from initial contact to the end of compaction for the two forming processes. It is shown that the contact normal force of a certain point in double compaction is lower than that in single compaction, this tendency is in good agreement with the contact force evolution in Fig. 6, indicating the potential of producing high property Fe-Al composite compact in double-action compaction in comparison with single-action compaction.

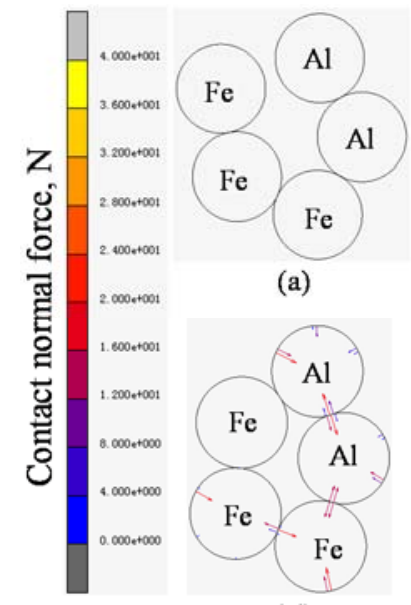

$\left(\mathrm{a}^{\prime}\right)$

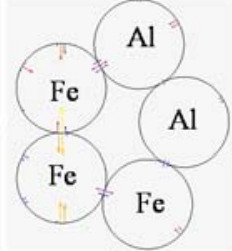

(b)

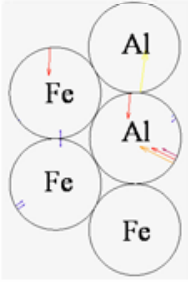

$\left(b^{\prime}\right)$

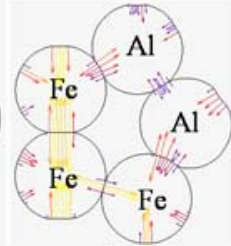

(c)

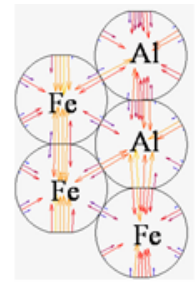

$\left(c^{\prime}\right)$

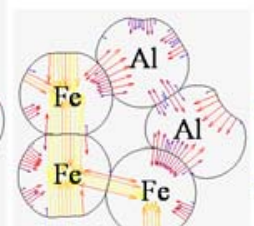

(d)

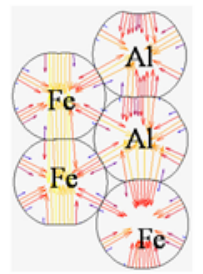

(d')

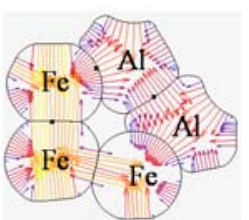

(e)

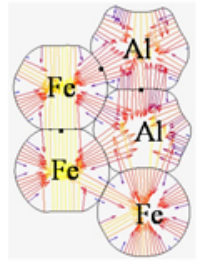

$\left(\mathrm{e}^{\prime}\right)$

Fig. 6 Contact normal force distributions in the local clusters in Fig. 5, where the dots schematically shown at the contact area between $\mathrm{Fe}-\mathrm{Fe}, \mathrm{Fe}-\mathrm{Al}$, and $\mathrm{Al}-\mathrm{Al}$ are the nodes of the initial contact point between these particles during compaction. 


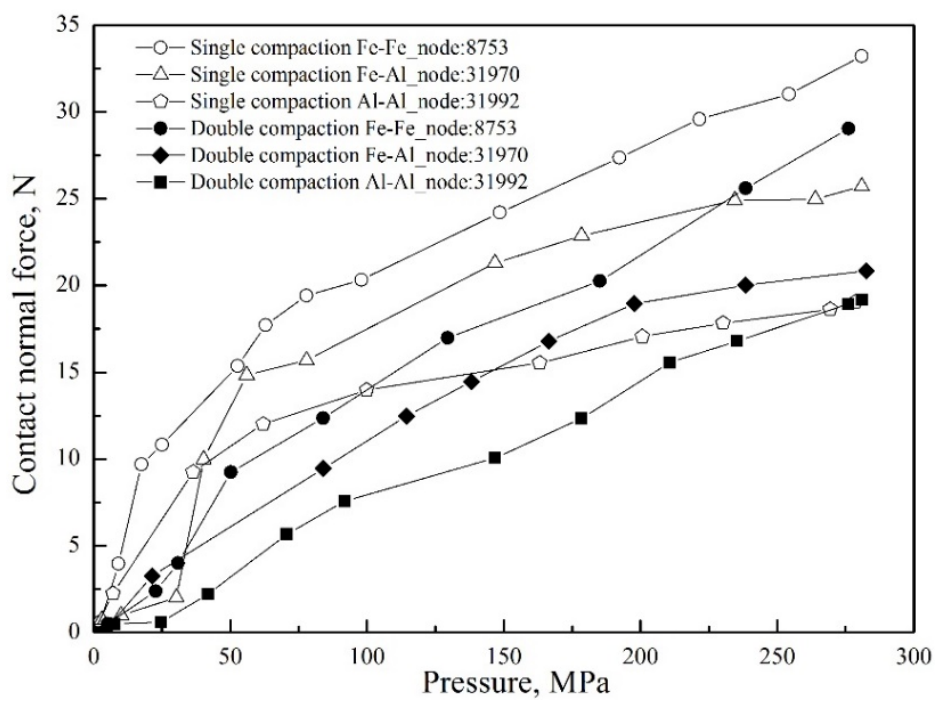

Fig. 7 The contact normal force evolution between two particles in the local cluster in Figs. 5 and 6, where the start of each curve is from the initial contact of corresponding two particles with the fixed node.

\section{Conclusions}

The compaction of Fe-Al composite powder (with $20 \mathrm{wt} \% \mathrm{Al}$ ) subjected to double-action die compaction was modeled in 2D by multi-particle finite element method (MPFEM) from particulate scale. The macro and micro properties were characterized and compared with those from singleaction die compaction. And the densification mechanism has been identified. Following conclusions can be drawn.

(1) Both the double-action compaction and single-action compaction can all obtain the dense compacts with the same relative density at sufficiently high compression pressure, while the densification process as well as the micro properties in the final compacts are quite different. Analyses indicate that the former process is more effective and efficient than the latter one.

(2) Densification mechanism characterization indicates that particle rearrangement, which is the main cause for densification at initial compaction stage, can be more effectively improved in double-action compaction. And this phenomenon remains in the subsequent compaction stage. With the increase of compaction pressure, the densification mechanism gradually transfers to the plastic deformation of $\mathrm{Al}$ particles to fill their adjacent interstices.

(3) The stresses and contact normal forces in the final compact obtained by double-action compaction are lower than those obtained by single-action die compaction. And the stress and relative density distributions as well as the particle deformation are also more uniform, indicating that compared with single-action compaction, double-action compaction is more desirable in realizing high performance $\mathrm{Fe}-\mathrm{Al}$ composite compacts.

\section{Acknowledgement}

The authors are grateful to the National Natural Science Foundation of China (No. 51374070) and Fundamental Research Funds for Central Universities of China (N162505001) for the financial support of current work.

\section{References}

[1] K. Natesan, P.F. Tortorelli, in: S.C. Deevi, V.K. Sikka, P.J. Maziasz, R.W. Cahn (Eds.), International Symposium on Nickel and Iron Aluminides: Processing, Properties, and Applications, ASM International, Materials Park, OH, 1996, pp. 265.

[2] S.C. Deevi, V.K. Sikka, Nickel and iron aluminides: an overview on properties, processing, and applications, Intermetallics 4 (1996) 357-375. 
[3] R. Subramanian, J.H. Schneibel, Processing iron-aluminide composites containing carbides or borides, JOM 49 (8) (1997) 50-54.

[4] S.C. Deevi, V.K. Sikka, C.T. Liu, Processing, properties, and applications of nickel and iron aluminides, Prog. Mater. Sci. 42 (1997) 177-192.

[5] N.S. Stoloff, Iron aluminides: present status and future prospects, Mater. Sci. Eng. A 258 (1998) $1-14$.

[6] C.T. Liu, Recent advances in $\mathrm{B}_{2}$ iron aluminide alloys: deformation, fracture and alloy design, Mater. Sci. Eng. A 258 (1998) 84-98.

[7] K. Natesan, Corrosion performance of iron aluminides in mixed-oxidant environments, Mater. Sci. Eng. A 258 (1998) 126-134.

[8] V.K. Sikka, D. Wilkening, J. Liebetrau, B. Mackey, Melting and casting of FeAl-based cast alloy, Mater. Sci. Eng. A 258 (1998) 229-235.

[9] S. Gedevanishvili, S.C. Deevi, Processing of iron aluminides by pressureless sintering through $\mathrm{Fe}+\mathrm{Al}$ elemental route, Mater. Sci. Eng. A 325 (2002) 163-176

[10] R.S. Sundar, D.H. Sastry, Y.V.R.K. Prasad, Hot workability of as-cast $\mathrm{Fe}_{3} \mathrm{Al}-2.5 \% \mathrm{Cr}$ intermetallic alloy, Mater. Sci. Eng. A 347 (2003) 86-92.

[11] F.Q. Lang, Z.M. Yu, S. Gedevanishvili, Corrosion behavior of Fe-40Al sheet in $\mathrm{N}_{2}-11.2 \mathrm{O}_{2}-$ 7.5 $\mathrm{CO}_{2}$ atmospheres with various $\mathrm{SO}_{2}$ contents at $1273 \mathrm{~K}$, Intermetallics 11 (2003) 135-141.

[12] M. Amaya, M.A. Espinosa-Medina, J. Porcayo-Calderon, High temperature corrosion performance of FeAl intermetallic alloys in molten salts, Mater. Sci. Eng. A 349 (2003) 12-19.

[13] F.Q. Lang, Z.M. Yu, S. Gedevanishvili, S.C. Deevic, S. Hayashid, T. Naritadet, Sulfidation behavior of Fe-40Al sheet in $\mathrm{H}_{2}-\mathrm{H}_{2} \mathrm{~S}$ mixtures at high temperatures, Intermetallics 12 (2004) 469475.

[14] H.Z. Kang, C.T. Hu, Swelling behavior in reactive sintering of Fe-Al mixtures, Mater. Chem. Phys. 88 (2004) 264-272.

[15] J.M. Guilemany, N. Cinca, L. Casas, E. Molins, Ordering and disordering processes in MA and MM intermetallic iron aluminide powders, J. Mater. Sci. 44 (8) (2009) 2152-2161.

[16] P.Z. Shen, M. Song, H.Y. Gao, Y.H. He, J. Zou, N.P. Xu, B.Y. Huang, C.T. Liu, Structural characteristics and high-temperature oxidation behavior of porous $\mathrm{Fe}-40$ at. \% $\mathrm{Al}$ alloy, M. Mater. Sci. 44 (2009) 4413-4421.

[17] P. Han, X.Z. An, Y.X. Zhang, Z.S. Zou, FEM modeling on the compaction of Fe and Al composite powders, J. Min. Metall. B 51 (2) B (2015) 163-171.

[18] P. Han, X.Z. An, Y.X. Zhang, F. Huang, H.T. Fu, X.H. Yang, Z.S. Zou, Particulate scale MPFEM modeling on compaction of Fe and Al composite powders, Powder Technol. (2016) DOI: 10.1016/j.powtec.2016.11.021.

[19] D.G. Morris, in: S.C. Deevi, V.K. Sikka, P.J. Maziasz, R.W. Cahn (Eds.), International Symposium on Nickel and Iron Aluminides, ASM International, Materials Park, OH, 1997, pp. 73.

[20] V.K. Sikka, in: S.C. Deevi, V.K. Sikka, P.J. Maziasz, R.W. Cahn (Eds.), International Symposium on Nickel and Iron Aluminides, ASM International, Materials Park, OH, 1997, pp. 361.

[21] E. Godlewska, S. Szczepanik, R. Mania, J. Krawiarz, S. Koziñski, FeAl materials from intermetallic powders, Intermetallics 11 (2003) 307-312. 
[22] W. Wu, G. Jiang, R.H. Wagoner, G.S. Daehn, Experimental and numerical investigation of idealized consolidation, part 1: static compaction, Acta Mater. 48 (2000) 4323-4330.

[23] X.Z. An, R.Y. Yang, K.J. Dong, R.P. Zou, A.B. Yu, Micromechanical simulation and analysis of one-dimensional vibratory sphere packing, Phys. Rev. Lett. 95 (2005) 205502.

[24] A.B. Yu, X.Z. An, R.P. Zou, R.Y. Yang, K. Kendall, Self-assembly of particles for densest packing by mechanical vibration, Phys. Rev. Lett. 97 (2006) 265501.

[25] X.Z. An, R.Y. Yang, R.P. Zou, A.B. Yu, Effect of vibration condition and inter-particle frictions on the packing of uniform spheres, Powder Technol. 188 (2008) 102-109.

[26] Y.L. Wu, X.Z. An, A.B. Yu, DEM simulation of cubical particle packing under mechanical vibration, Powder Technol. (2016) DOI: 10.1016/j.powtec.2016.09.029.

[27] Y.X. Zhang, X.Z. An, Y.L. Zhang, Multi-particle FEM modeling on microscopic behavior of 2D particle compaction, Appl. Phys. A 118 (3) (2015) 1015-1021.

[28] F. Huang, X.Z. An, Y.X. Zhang, A.B. Yu, Multi-particle FEM simulation of 2D compaction on binary Al/SiC composite powders, Powder Technol. (2016) (Submitted).

[29] I. Danaila, F. Hecht, A finite element method with mesh adaptivity for computing vortex states in fast-rotating Bose-Einstein condensates, J. Comput. Phys. 229 (2010) 6946-6960.

[30] H.R. Hiester, M.D. Piggott, P.A. Allison, The impact of mesh adaptivity on the gravity current front speed in a two-dimensional lock-exchange, Ocean Model. 38 (1-2) (2011) 1-21.

[31] P. Mostaghimi, I.M.S.K. Ilankoon, S.J. Neethling, Use of mesh adaptivity in simulation of flow in packed beds-A case study, Miner. Eng. 63 (4) (2014) 157-163.

[32] T. Lucht, Finite element analysis of three dimensional crack growth by the use of a boundary element sub model, Eng. Fract. Mech. 76 (14) (2009) 2148-2162.

[33] R.M. German, Particle Packing Characteristics, Metal Powder Industries Federation, Princeton, New Jersey (1989).

[34] A.K. Eksi, A.H. Yuzbasioglu, Effect of sintering and pressing parameters on the densification of cold isostatically pressed Al and Fe powders, Mater. Design 28 (2007) 1364-1368.

[35] R.W. Heckel, Density-pressure relationships in powder compaction, Trans. Metall. Soc. AIME 221 (1961) 671-675.

[36] R. Ramberger, A. Burger, On the application of the Heckel and Kawakita equations to powder compaction, Powder Technol. 43 (1985) 1-9. 